\title{
Structural Analysis of Extruded Fiber Components of Orange Pulp
}

\section{Miguel Ángel Larrea Céspedes ${ }^{1}$, José Luis Ramírez Ascheri²*, Fernando Martínez Bustos ${ }^{3}$, Ronel Joel Bazán-Colque ${ }^{4}$}

\author{
${ }^{1}$ Universidad Señor de Sipan, Lambayeque, Perú \\ ${ }^{2}$ Embrapa Food Technology, Food Extrusion and Physical Properties Laboratory, Rio de Janeiro, Brazil \\ ${ }^{3}$ CINVESTAV-UNIDAD QUERÉTARO, Querétaro, México \\ ${ }_{4}^{4}$ Postgraduate Program in Food Science and Technology, Federal Rural University of Rio de Janeiro, Seropédica, RJ, Brazil \\ Email: ^jose.ascheri@embrapa.br
}

How to cite this paper: Céspedes, M.Á.L., Ascheri, J.L.R., Bustos, F.M. and Bazán-Colque, R.J. (2021) Structural Analysis of Extruded Fiber Components of Orange Pulp. Journal of Biosciences and Medicines, 9, 6-20.

https://doi.org/10.4236/jbm.2021.911002

Received: October 6, 2021

Accepted: November 7, 2021

Published: November 10, 2021

Copyright (c) 2021 by author(s) and Scientific Research Publishing Inc. This work is licensed under the Creative Commons Attribution International License (CC BY 4.0)

http://creativecommons.org/licenses/by/4.0/

\begin{abstract}
X-ray diffractograms, optic and electronic microscopy were used to study the structural changes on extruded orange pulp using a Brabender ${ }^{\circledR}$ laboratory single-screw extruder (GNF 1014/2, 20:1, L/D). The results showed that most of the cellulose would be in the amorphous state, with small crystalline areas in the angular region of $2 \theta=14.5^{\circ}$. The evaluated extrusion conditions did not affect the crystallinity of the raw cellulose, maintaining the size of the crystalline regions in the angular region of $2 \theta=22.5^{\circ}$. Neutral detergent solubilized the crystalline areas of potassium citrate and cellulose, formed during the extrusion process. However, these conditions did not affect the crystallinity of the raw cellulose. In addition, no change was observed in the crystallinity of pectin. The electron microphotographs allowed for the estimation of the heterogeneity of orange pulp and assessment of the difference of resistance between the walls of the buds and juice vesicles. Thus, it was demonstrated that during the extrusion process most of the porosity and the cellular structure of the endocarp remained unaltered.
\end{abstract}

\section{Keywords}

Orange Pulp, X-Rays Diffraction, Optic Microscopy, Electron Microscopy

\section{Introduction}

The production of oranges in Brazil reached more than 17 million metric tons in 2019, an increase of around 2.3 percent in comparison to the previous year [1]. The number of residues accounted for 50 percent of the whole fruit mass. 
Orange pulp is the main by-product during the processing of citrus fruits, and a latent load to environment without further treatment [2]. The peel of citrus fruits is a byproduct of processing of orange juice that is not used; recent researches have reported that the orange peel is rich in antioxidants, fiber and bioactive compounds. The incorporation of meat and bakery products improves their texture and color [2].

Orange fruits have three parts: 1) the skin, called epicarp or flavedo, in this part essential oils and carotenoids are present, as main components, 2) mesocarp or albedo, here found pectins and hemicelluloses, and 3) endocarp, the edible part of the fruit, formed mainly by 9 to 13 segments similar to triangles. In the inward of each segment are located the juice vesicles, which are linked to the capillary membrane for fine coats or trichomes, that gradually accumulate juice during the fruit maturation. In orange can be found up to six staple fiber sources, located in the vesicles of juice, core, albedo, flavedo membranes and seeds [3]. The pulp is composed of pieces of membrane materials from the ruptured juice sacs and segment walls, contributing to the texture and mouthfeel of citrus juice. In the orange juice, pulp is characterized as either "sinking" or "floating": the "sinking" pulp is an integral part of the juice and consists of small particles $(<0.5 \mathrm{~mm})$ which settle with time; the floating pulp consists of the larger membrane pieces and broken juice vesicles removed through the finishers [4]. A manual dissection of the components of mature orange (Pineapple orange) showed the following distribution in weight: flavedo and albedo (37\%); juice vesicles (10\%); membranes (19\%); seeds (8\%) and juice (26\%) [5].

Orange bagasse is a dietary fiber source because it contains both soluble and insoluble dietary fiber: $57 \%$ total fiber (db: dry basis,), $476 \mathrm{~g} / \mathrm{kg}$ insoluble fiber, and $94.1 \mathrm{~g} / \mathrm{kg}$ soluble fiber [6].

The dietary fiber compositions of the differently dried samples of insoluble dietary fiber, soluble dietary fiber and total dietary fiber contents were in the range of $29.49 \%-33.53 \%, 7.08 \%-8.48 \%$ and $37.86 \%-41.84 \%(\mathrm{db})$, respectively. Different drying methods, namely hot air-drying, vacuum-drying and low-pressure superheated steam-drying, at $60^{\circ} \mathrm{C}-80^{\circ} \mathrm{C}$ did not significantly affect the fiber composition. The citrus fibers are mostly composed of carbohydrates, which make up approximately $80 \%$ of the total composition. The most prevalent polysaccharides in the citrus fibers are pectin (42.25\%), hemicellulose, and lignin (15.95\%). Considering the source of the raw material, this is not a surprise and is consistent with others who also report similar amounts of pectin and cellulose in citrus fiber [7].

This high fiber content makes it a potential alternative fiber source. In pectin and hemicelluloses, major components are arabinose, galactose, and galacturonic acid, whereas rhamnose, glucose and xylose are very less [8]. In addition to the well-recognized abilities of dietary fiber to retard glucose absorption and inhibit gastrointestinal enzymes, dietary fiber has recently been shown to possess mycotoxin adsorption capability [9].

The dietary fiber of citrus fruit is a higher quality because has a higher soluble 
dietary fiber ratio and associated bioactive compounds (flavonoids, polyphenols, carotenoids and vitamin C) with antioxidant properties, which may provide additional health-promoting effects [10].

The by-products generated by the citrus juice industries are sources of dietary fiber but are commonly used in animal feed or fertilizer. However, due to their high fiber content, they can be used as ingredients in food [11]. The potential hypoglycemic effects of extruded orange pulp suggest that orange pulp is a good and abundant dietary fiber resource that could be of great benefit in controlling glucose levels in the blood. It could also be added to high-fiber foods as a low-calorie bulk ingredient to reduce the calorie level [12]; It is assumed that during high-shear treatment rearrangements within the fruit fiber structure take place, including disintegration of cells and cell wall fragments and the formation of a three-dimensional network.

Most of the cellulose orange pulp would be in amorphous state, showing small crystalline regions, mainly in extruded samples [13].

The application of heat and moisture generate one marked increase in the index of crystallinity of cellulose. While, cellulose with higher initial crystallinity showed only small changes in crystallinity. Also, the pre-processing with chemical substances such as: alkaline hydrogen peroxide, hydrochloric acid, neutral and acid originated an outstanding increment in the crystallinity of pure cellulose [11]. Influences of pretreatment from on selected characteristics of dietary fiber from orange pulp powder (washing, blanching, soaking in ethanol), drying methods (hot air drying, infrared-drying, microwave-drying and drying temperature) confirmed in scanning electron micrograph images (SEM) that washing and blanching led to the losses of water-soluble components and resulted in porous and breakage structures capacity. This in turn implies, according to these studies, that the porous structure of the fiber is an important parameter affecting the change in diverse properties. Microscopy results, on the other hand, verified an increase in the porosity of the fiber after pretreatments also, statistical analysis, permit verified that fiber structure played a more important role in the functional properties. This is again because some components of the residues were lost during the pretreatments, resulting in turn in an increase in the surface area and porosity, which facilitated entrapment of glucose molecules [14].

The aim of this work was to study the modifications on the crystallinity components of fiber orange pulp during extrusion process and the effect of neutral detergents on these components.

\section{Material and Methods}

\subsection{Raw Material}

Washed orange pulp (90\% moisture content) was obtained from Citrosuco Paulista S. A. (Limeira, SP, Brazil). The samples were dried to about $9 \%$ moisture content in a forced-air oven at $80^{\circ} \mathrm{C}$ for $12 \mathrm{~h}$. The samples were milled using a Brabender Quadrumat Senior Mill (Duisburg, Germany) to generate products 
with a particle-size $<1 \mathrm{~mm}$ to aid in further analyses.

\subsection{Extrusion Process}

Extrusion experiments were performed using a laboratory Single Screw Extruder 19/25 (Brabender ${ }^{\circledR}$, Inc., Duisburg, Germany) with a barrel of $380 \mathrm{~mm}$ in length and $19 \mathrm{~mm}$ of diameter. The barrel had three sections with electric heaters independently controlled and a 3:1 compression ratio screw. A die with $4 \mathrm{~mm}$ diameter was used. Compressed air was circulated around the barrel to maintain a precise control of the temperature of the barrel and die assemble. Flour samples were fed by a forced feeding. The feed rate was maintained constant at $70 \mathrm{~g} / \mathrm{min}$ (dry matter). The extrusion conditions were: barrel temperature $\left(145^{\circ} \mathrm{C}, 167^{\circ} \mathrm{C}\right.$, and $\left.125^{\circ} \mathrm{C}\right)$, feed moisture content $(22 \%, 30 \%$, and $38 \%)$, and screw speed $(126$, 160 , and $160 \mathrm{rpm}$ ). Samples were dried in a forced-air oven at $60^{\circ} \mathrm{C}$ for $12 \mathrm{~h}$, and milled using a roller mill (Brabender ${ }^{\circledR}$ Inc., Duisburg, Germany) to produce particles with a size $<0.840 \mathrm{~mm}$ and stored in polyethylene bags for further analysis.

\subsection{X-Ray Diffraction Analysis}

The X-ray powder diffraction analysis was performed on dried samples according to the method of Artz et al. [15]. The insoluble solid fractions from extruded fiber orange pulp and raw fiber orange pulp were prepared following the method of Gourgue et al. [16].

The fibers were milled and sieved with particle size $<150 \mu \mathrm{m}$, then were densely packed into an $\mathrm{Al}$ frame. X-ray diffraction patterns and analyzed using a Philips PW 1170 diffractometer operating at $40 \mathrm{kV}, 30 \mathrm{~mA}$ with $\mathrm{Cu} \mathrm{K}$ radiation wavelength $\lambda=1.5406 \AA$. Data were collected from $0-30^{\circ}$ on a $2 \theta$ scale with a step size of $0.02^{\circ}$ and reported as interplanar d-spacing values expressed in $\AA$.

The effects of some chemical substances in the crystallinity of extruded and raw fiber pulp were carried out in fiber neutral detergent [17], and the samples of pectin were previously isolated by extraction with hydrochloride acid $\mathrm{pH}=$ 2.2 [5]. The crystallinity (\%) was calculated by normalizing the integrated diffracted intensity over the measured $2 \theta$ range to the integrated noncoherent intensity. The noncoherent intensity was obtained by subtracting the sharp diffraction peaks from the total diffraction pattern using the software Diffract/AT from Socobin VI: 2. Measurements of each sample were performed in duplicate.

\subsection{Optic Microscopy}

Raw and extruded orange pulp $\left(145^{\circ} \mathrm{C}\right.$ barrel temperature, $22 \%$ moisture content and $126 \mathrm{rpm}$ screw speed) were hydrated in distilled water. Samples were stained with solutions of safranin, and blue of toluidine for effect of contrast and histochemical analysis. After, that the stained samples were placed on nylon sieve washed to remove excess of stain and placed on glass slide mounted in glycerin under a glass cover slip. 


\subsection{Scanning Electron Microscopy}

The samples were stored with silica, at $35^{\circ} \mathrm{C}$ for 10 days, to remove the residual moisture. Sections were adhered to stubs, coated with $\mathrm{Au}-\mathrm{Pd}$ alloy in high vacuum and examined using the scanning electron microscope Jeol J-SM, $5800 \mathrm{LV}$ with $15 \mathrm{kV}$ of acceleration [15].

\section{Results and Discussion}

\subsection{X-Ray Diffraction Analysis}

In Figures 1-3 are shown the intensities of diffraction of rays-x of raw and extruded orange pulp. (A) raw orange pulp; (B) extruded orange pulp $\left(145^{\circ} \mathrm{C}\right.$ barrel temperature, $22 \%$ moisture content, and $126 \mathrm{rpm}$ screw speed); (C) extruded orange pulp $\left(167^{\circ} \mathrm{C}\right.$ barrel temperature, $30 \%$ moisture content, and $160 \mathrm{rpm}$ screw speed); (D) extruded pulp $\left(125^{\circ} \mathrm{C}\right.$ barrel temperature, $38 \%$ moisture content, $160 \mathrm{rpm}$ screw speed).

Figure 1 shows the previously washed samples with solution of ethanol for recovery of insoluble solids in alcohol. All the samples showed higher peaks, with little resolution with values of approximately $2 \theta=12^{\circ}$ and interval of $2 \theta$ from $20^{\circ}$ to $23^{\circ}$. In addition, it was observed in all the extruded samples, the presence of small peaks in angular regions of $2 \theta=14.5^{\circ}$ and $2 \theta=24.5^{\circ}$ and in raw orange pulp absence of peaks in the angular regions $2 \theta=14.5^{\circ}$. The peaks located at $2 \theta=12^{\circ}$ and $21.5^{\circ}$ would be attributed to the presence of pectin (Figure 3).

The peaks localized in the region $2 \theta=24.5^{\circ}$ are relevant to potassium, or some compounds of potassium, probably monobasic potassium citrate with sensible crystallinity mainly in the diffractograms A and D. This affirmation is supported by the studies of Koch [18]. This researcher isolated crystalline agglomerates in samples of concentrated orange juice, demonstrating that in these agglomerates the citrate and potassium ions showed a stoichiometric relation of

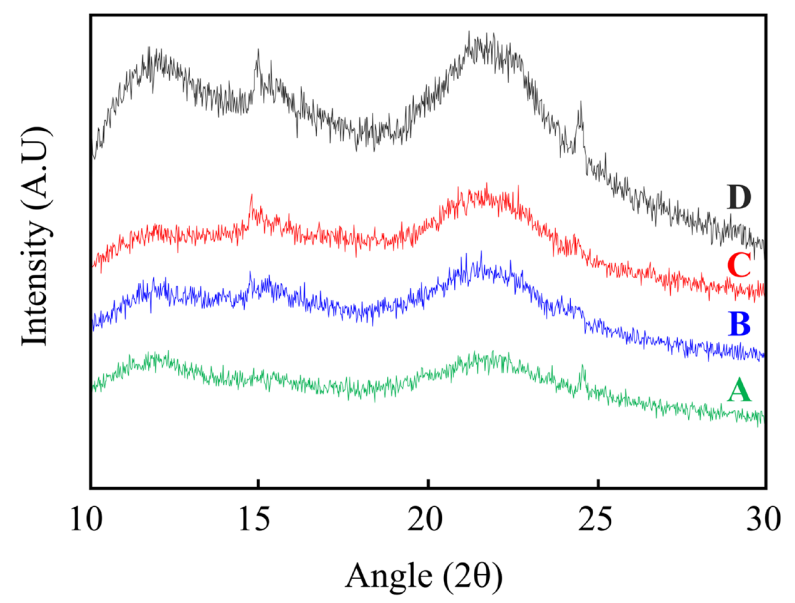

Figure 1. X-ray diffractograms of insoluble solids in alcohol from orange pulp. A: without extrusion; B: with extrusion $\left(145^{\circ} \mathrm{C}, 22 \%\right.$ moisture, $\left.126 \mathrm{rpm}\right)$; C: with extrusion $\left(167^{\circ} \mathrm{C}, 30 \%\right.$ moisture, $\left.160 \mathrm{rpm}\right)$; D: with extrusion $\left(125^{\circ} \mathrm{C}, 38 \%\right.$ moisture, $\left.160 \mathrm{rpm}\right)$. 


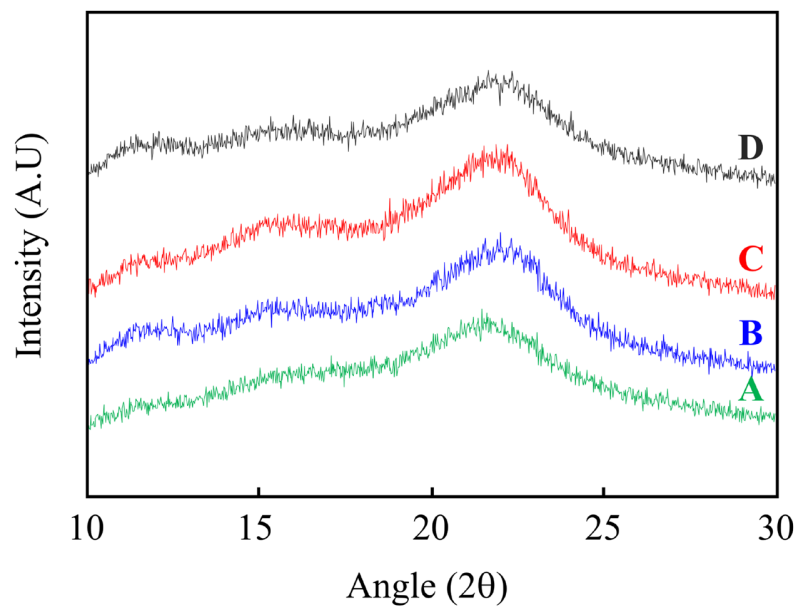

Figure 2. X-ray diffractograms of neutral detergent fibers from orange pulp. A: without extrusion; B: with extrusion $\left(145^{\circ} \mathrm{C}, 22 \%\right.$ moisture, $\left.126 \mathrm{rpm}\right)$; C: with extrusion $\left(167^{\circ} \mathrm{C}\right.$, $30 \%$ moisture, $160 \mathrm{rpm})$; D: with extrusion $\left(125^{\circ} \mathrm{C}, 38 \%\right.$ moisture, $\left.160 \mathrm{rpm}\right)$.

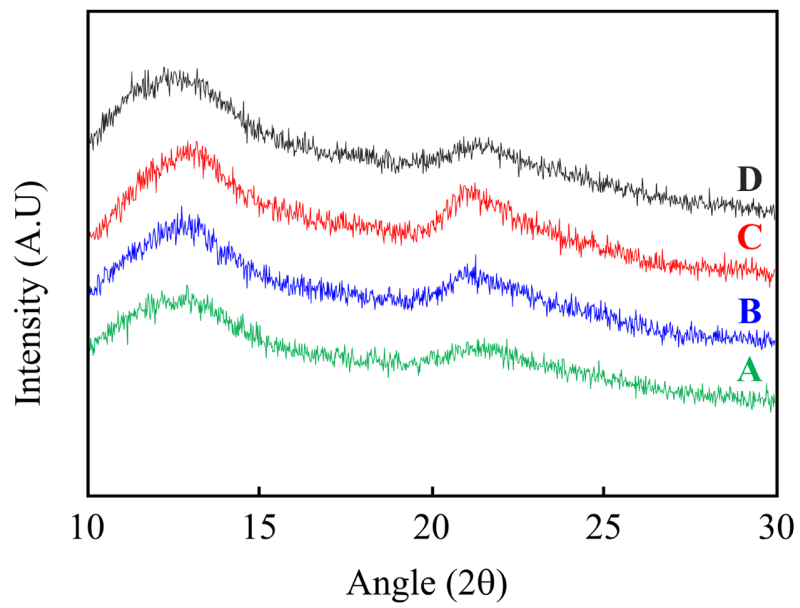

Figure 3. X-ray diffractograms of pectin from orange pulp. A: without extrusion; B: with extrusion $\left(145^{\circ} \mathrm{C}, 22 \%\right.$ moisture, $\left.126 \mathrm{rpm}\right)$; C: with extrusion $\left(167^{\circ} \mathrm{C}, 30 \%\right.$ moisture, 160 $\mathrm{rpm})$; D: with extrusion $\left(125^{\circ} \mathrm{C}, 38 \%\right.$ moisture, $\left.160 \mathrm{rpm}\right)$.

$1 \mathrm{~mol}$ of citrate: $1 \mathrm{~mol}$ of potassium, being the monobasic potassium citrate the major component of these crystalline agglomerates. These peaks showed lower intensity when the barrel temperatures were higher than $145^{\circ} \mathrm{C}$ and $167^{\circ} \mathrm{C}$.

Kimball [19], reported the presence of crystalline agglomerates in concentrated orange juice with greater acidity from Florida State, USA. By other hand, the peaks found in the regions $2 \theta=14.5^{\circ}$ and $2 \theta=22.5^{\circ}$ are proper of cellulose. The natural structure of the cellulose shows a degree of polymerization from 1.000 the 15.000 glucose residues anhydre [9].

Alankar et al. [20], reported similar results for cellulose raw cotton. These researchers studied the effect of some chemical reagents and the effect of heat on the crystallinity of cellulose, using sigmacel 100 and sigmacel 50 as cellulose sources. Their finds showed that most of the cellulose orange pulp would be in amorphous state, showing small crystalline regions, mainly in extruded samples, 
where, they observed formations of small crystalline regions at $2 \theta=14.5^{\circ}$ when compared with raw pulp, this intensity decreased gradually as the temperature of the process was increased.

This behavior would be explained by the application of combined effects of heat, moisture content and mechanical attrition during the extrusion process. Alankar et al. [20], reported similar trends with the application of heat and moisture with an increasing in the relative crystallinity of sigmacel 100 (cellulose of moderate crystallinity). Also, these researchers found that heating at $50^{\circ} \mathrm{C}$ the cellulose of moderate crystallinity (SC100) in aqueous medium, was enough to generate one marked increase in the index of crystallinity, and this increase was higher at higher temperatures. Contrary to this behavior, and using the same processing conditions, cellulose with higher initial crystallinity (monocrystal cellulose) showed only small changes in crystallinity. In addition, they reported that the pre-processing with chemical substances such as: alkaline hydrogen peroxide, hydrochloric acid, neutral and acid detergents used to recover cellulose of vegetal products, originated an outstanding increment in the crystallinity of pure cellulose (SC100).

In the present study, the size of the crystalline regions was determined from the width to the half-height of the peak registered at $2 \theta=22.5^{\circ}$ using commercial

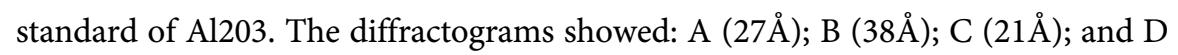
$(23 \AA)$, and did not show differences in this level between extruded and raw samples. Research conducted by Artz et al. [15], reported that the extrusion process did not modify the structure of fiber maize, without any significant change in the crystallinity of the cellulose; therefore, no change took place in the profile of rays- $x$ diffraction. The polymerization degree varies greatly, depending on the source and of the type of processing to which cellulose had been submitted. The cellulose chains are added to form elementary fibrils that are linked through hydrogen linkages of adjacent chains resulting in the crystallinity of the cellulose [21].

Thus, the cellulose shows where the chains are parallelly ordered, called crystalline zones, which are separate for regions less ordered, known as amorphous. In this way, the cellulose is considered as a paracrystalline substance, and not a perfect crystal. The average longitude of the crystalline regions is approximately $500 \AA$ for native cellulose, and $150 \AA$ for regenerated cellulose, estimating the proportion of the crystalline material in $50 \%-90 \%$ [22].

Figure 2 shows the diffractograms reported by Van Soest \& Jones [17] of samples previously treated with neutral detergent, in this study the fiber was basically formed by cellulose, hemicelluloses and lignin. The analysis showed the presence of wide peaks in the region $2 \theta=22.5^{\circ}$ of cellulose with low degree of crystallinity, due to it showed small crystalline areas with sizes of A ( $25 \AA)$, B (23 $\AA), C(20 \AA)$ and $\mathrm{D}(23 \AA)$, indicating that the action of neutral detergent did not modify the crystallinity of the samples at this level. The peaks between the values of $2 \theta=12^{\circ}, 2 \theta=14.5^{\circ}$ and $2 \theta=24.5^{\circ}$ proper of pectin, extruded cellulose slightly crystallized and potassium citrate, respectively, were not registered as consequence of the solubilization with neutral detergent. Gilbert \& Tsao [23] es- 
timated that the cellulose approximately shows $85 \%$ of crystalline regions and $15 \%$ of amorphous regions. The greater part of hemicelluloses is composite of pentoses and hexoses, and frequently shows main chain and branches, being therefore generally amorphous [24]. The structure of hemicelluloses varies greatly, depending on the origin of the plant. Combining thermal and mechanical energies, extrusion process affects the chemical structure of dietary fibers, and it may impart new functional properties, i.e., enhancing viscosity or gel forming ability. For example, extrusion cooking has been applied to onion waste derived from the white outer fleshy scale leaves [25]. After extrusion, an increase in solubility of the cell wall pectin polymers and hemicelluloses was observed along with swelling of the cell wall material, while carbohydrate composition of the cell wall material remained unaffected. With such modifications in solubility and apparent viscosity, the onion waste material can be used as a potential source of $\mathrm{DF}$, leading to benefits when applied to new formulations to produce extruded foods. Among other technological food processing procedures, such as fractionation through drying of materials [26].

In Figure 3 is shown the diffractograms of samples of isolated pectin extracted with acid. All the samples showed higher peaks at values $2 \theta=12^{\circ}$ and $2 \theta=21.5^{\circ}$ proper of pectin with lower degree of crystallinity, the sizes of the crystalline areas observed in this region of $2 \theta=21.5^{\circ}$, were A $(33 \AA), \mathrm{B}(28 \AA), \mathrm{C}(37 \AA)$, and $\mathrm{D}(43 \AA)$. In this figure the peaks of cellulose and potassium citrate were not registered, due to that they were separate during the process of extraction of pectin.

\subsection{Optic Microscopy}

Optic microscopy of raw and extruded orange pulp stained with safranin, and blue of toluidine are shown in Figure 4 and Figure 5 respectively. The samples were hydrated with the purpose of desegregating the samples and facilitating the extraction of pectic compounds from the tissues Also, it was evident that the orange pulp is morphologically characterized by the juice vesicles that conserved pectic structure, evidenced for the area stained with blue of toluidine in raw and extruded samples (Figure 5).

Figure 4 showed optic micrographs of the orange pulp stained with safranin. A: raw orange pulp, shows juice vesicles at $32 \times$ increasing; the internal shading of the walls is a device of illumination due to wavy surface of the walls of the tissue; B: raw orange pulp, it shows at $125 \times$ increasing that the juice vesicles or endocarp of buds show the structured tissue, even that they are kneaded and cut; C: extruded orange pulp and D: show at $125 \times$ increasing that the extrusion process did not disintegrate the portions most resistant of endocarp from buds.

The juice vesicles empty and elongated, stained with violet coloration, shows richer composition in pectic material; C and D extruded samples show succession of separated forms in endocarp more resistant, cellulosic of the walls of the bud, and juice vesicles of pectic nature adhered to buds.

Figure 5 showed optic micrographs of the orange pulp stained with blue of toluiduin (125x). A: raw orange pulp, blue staining in regions of endocarp shows 

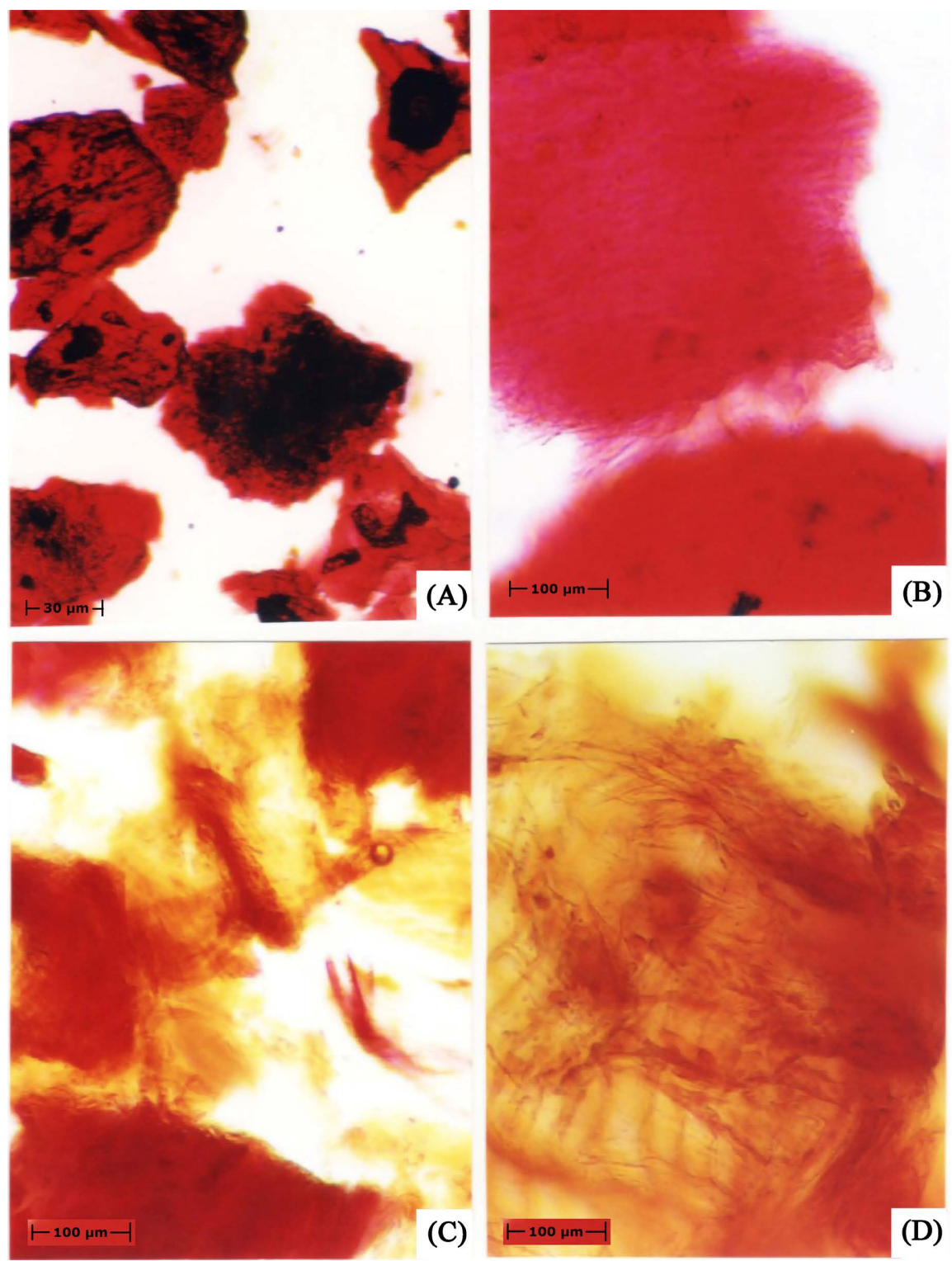

Figure 4. Optic micrographs of the orange pulp stained with safranin. (A) Raw orange pulp, shows juice vesicles at $32 \times$ increasing; (B) Raw orange pulp, shows juice vesicles at 125x increasing; (C) Extruded orange pulp, show at $125 \times$ increasing; (D) Extruded orange pulp, show at $125 \times$ increasing.

where the cellulose predominate, and regions in violet rose, where the pectin confers methacromaticity to the stain; B: extruded orange pulp, in blue stain the cellulosic tissue of endocarp is little dense, and the cellulolitic orifices are being taken away in the inferior margin of the figure. The vesicles juice empty and elongated, in methacromaticity violet staining, demonstrate a composition more rich in pectic material; $\mathrm{C}$ and $\mathrm{D}$ extruded orange pulp showed succession of separated forms of endocarp, these fragments of walls of gomo are more resistant and cellulosic, and vesicles of juice of nature more pectic, adhered to the gomos.

However, with reference to molecular mass, prevailed the presence of cellulosic material of the walls of the buds that lost little molecular mass during the 

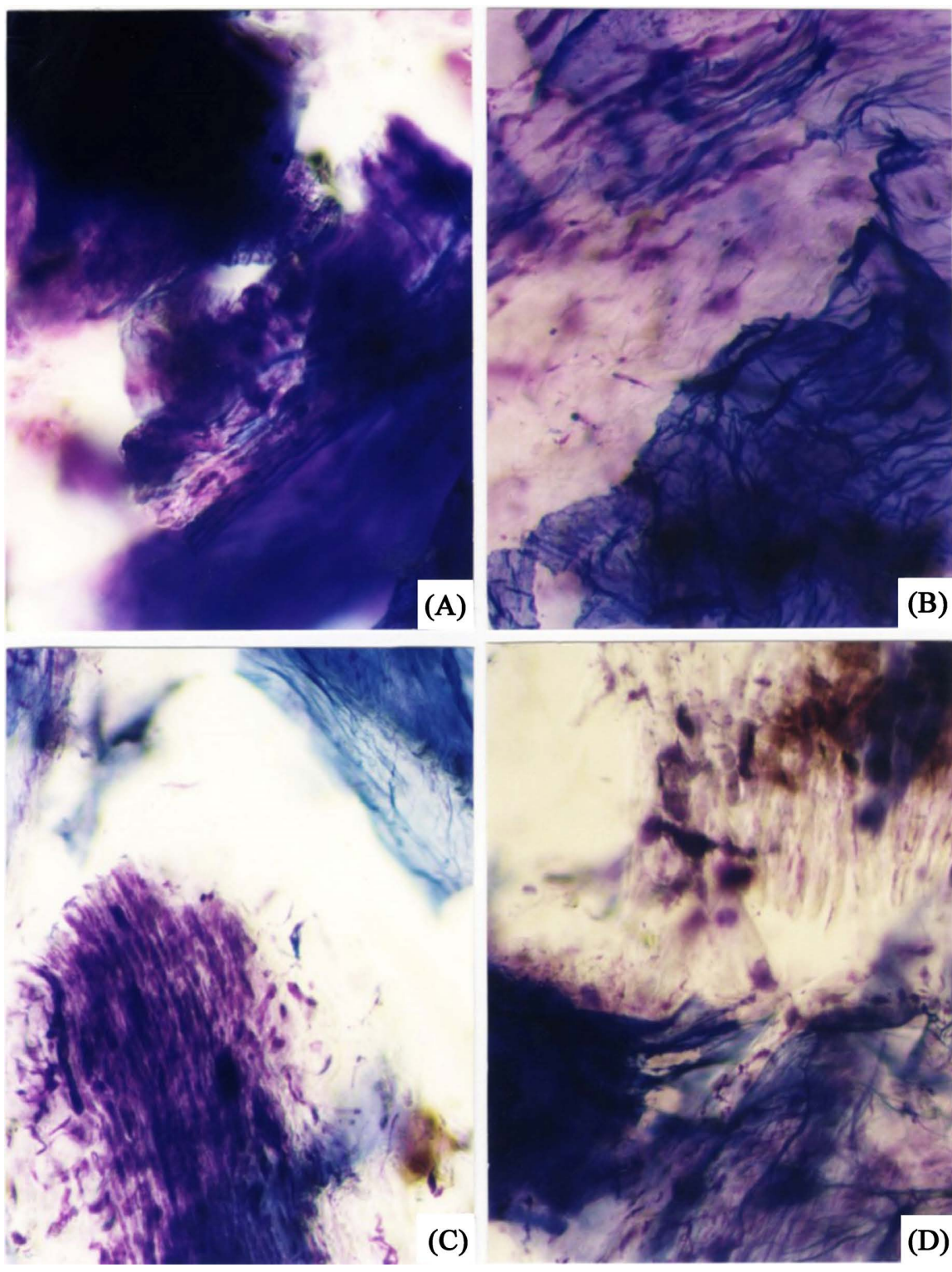

Figure 5. Optic micrographs of the orange pulp stained with blue of toluiduin $(125 \times)$. (A) Raw orange pulp; (B) Extruded orange pulp; (C) (D) Extruded orange pulp showed succession of separated forms of endocarp these fragments of walls of gomo are more resistant and cellulosic, and vesicles of juice of nature more pectic, adhered to the gomos.

extrusion process and conserved the porous structure.

The present study demonstrated that appropriate sample pretreatments could create more porous structure of dietary fiber that resulted in improved hydration and oil-holding properties and GDRI. However, such pretreatments led to the losses of dietary fiber components, which led to the reduction in the a-amylase inhibitory activity and in vitro AFB1 adsorption capacity. Fourier-transform infrared spectroscopy (FT-IR) results indeed confirmed the losses of the fiber functional groups during pretreatments. Microscopy results, on the other hand, verified an increase in the porosity of the fiber after pretreatments. 
Influences of drying methods on composition and statistical analysis revealed that it was the fiber structure that played a more important role in the functional properties.

\subsection{Scanning Electron Microscopy}

Due to the necessary dehydration of the samples, the differences between raw and extruded samples were reduced (Figure 6). The analysis demonstrated that dehydrated orange pulp conserved its porous structure and that; the extrusion process conserved the structure of the vegetal tissue and promotes discrete fragmentation. The porous structure of raw material and the unaltered structure of extruded sample are shown in Figure 6.
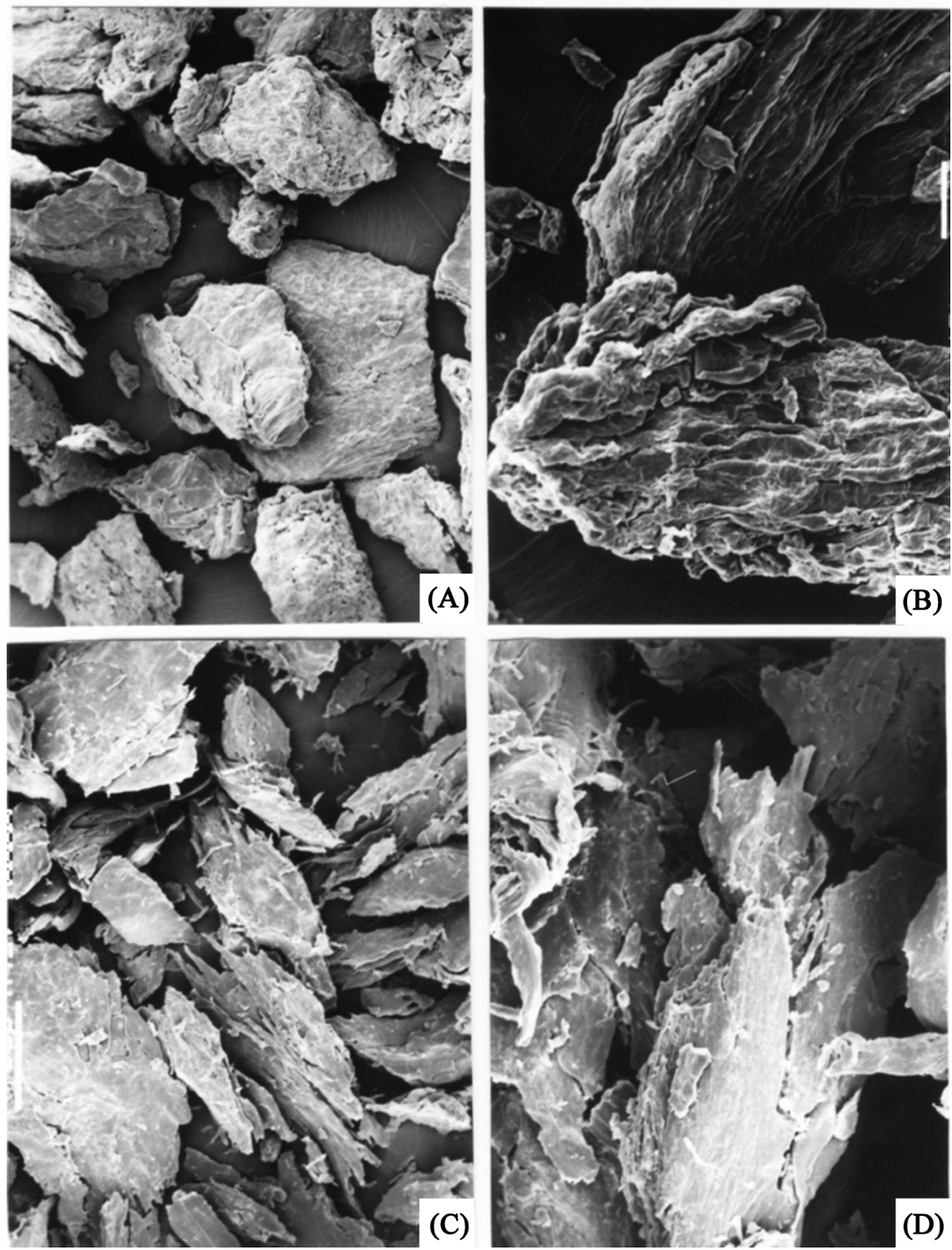

Figure 6. Electronic micrographs of extruded orange pulp. (A) (B) Raw orange pulp (15 $\mathrm{kV}, 100 \mathrm{~mm}, 100 \times$ and $15 \mathrm{kV}, 50 \mathrm{~mm}, 270 \times$, respectively); (C) (D) Extruded orange pulp, (15 kV, $200 \mathrm{~mm}, 95 \times$ and $15 \mathrm{kV}, 100 \mathrm{~mm}, 250 \times$, respectively). 
According to Sheltami et al. [27] the peaks located at around $22-23 \AA$ are originate from the cellulose crystals. Nevertheless, the peak at around $18 \AA$ indicates the amorphous background present in the fiber samples. The results of orange peel bers [28] indicate a degradation peak at around $163^{\circ} \mathrm{C}-170^{\circ} \mathrm{C}$. Scanning electron micrograph (SEM) images demonstrated that the surface of soluble dietary fiber (SDF) from orange peel treated by SE-SAS was rough and collapsed. It can be concluded that SDF from orange peel treated by SE-SAS has the higher potential to be applied as a functional ingredient in food products. Generally, literature suggest that treatments like extrusion and high-pressure application enhance, while grinding and peeling lower the water absorption capacity of fibers [29] possible decrease in the material's phenolic compounds [30].

Artz et al. [15], reported that the effect of the extrusion process in the structural conformation of staple fibers depend on the processing conditions, basically temperature. Thus, the extrusion of maize bran at $90^{\circ} \mathrm{C}$ barrel temperature, 50\% moisture content and $200 \mathrm{rpm}$ screw speed induced a little breaking of the fiber structure, while that temperatures of $150^{\circ} \mathrm{C}$ caused greater structural changes, in the same conditions of moisture content and screw speed.

Figure 6 Electronic micrographs of extruded orange pulp: A and B: raw orange pulp ( $15 \mathrm{kV}, 100 \mathrm{~mm}, 100 \times$ and $15 \mathrm{kV}, 50 \mathrm{~mm}, 270 \times$, respectively). The endocarp was formed by flattened fragments, with porous and irregular surfaces; $\mathrm{C}$ and D: extruded orange pulp ( $15 \mathrm{kV}, 200 \mathrm{~mm}, 95 \times$ and $15 \mathrm{kV}, 100 \mathrm{~mm}, 250 \times$, respectively). Small structure was broken up by the extrusion process; the modified cellulose did not conserve the structure of the fragments of endocarp.

\section{Conclusions}

Extrusion process did not diminish the size of the crystalline areas of the cellulose orange pulp. However, it induces the formation of small crystalline regions in the angular direction $2 \theta=14.5^{\circ}$. Neutral detergent solubilized the crystalline areas of cellulose orange pulp formed during the extrusion process in the region $2 \theta=14.5^{\circ}$. Thus, the crystalline structure of the monobasic potassium citrate solubilized, however, did not modify the crystallinity of the raw cellulose in the value $2 \theta=22.5^{\circ}$. However, it was not observed alteration in the crystallinity of extruded pectin, with relation to the pectin of raw pulp.

The microscopy study showed the heterogeneity of orange pulp, and assessment of the resistance of the walls of buds in relation to the extruded juice vesicles. Electronic microscopy also demonstrated that most of the porosity and the cellular structure were conserved and that the free pectin remains together with the cellulose involving it during the rehydration. The composition, images of citrus fibers in this study provide a much better understanding of the structure or form of citrus fibers and their functional properties.

\section{Acknowledgements}

The authors acknowledge the financial support of CAPES. 


\section{Conflicts of Interest}

The authors declare no conflicts of interest regarding the publication of this paper.

\section{References}

[1] Statista Research Department (2021) Brazil: Oranges Production Volume 2013-2019. Statista Research Department, New York.

[2] Cayres, C.A., Ascheri, J.L.R. and Couto, J.L.R. (2021) Evaluation of Nutritional Characteristics and Consumers' Acceptance of Gluten-Free Sweet Biscuits Made from Rice-Based Pregelatinized Composite Flours Containing Orange Pomace and Soy Protein Isolate. SN Applied Sciences, 3, Article No. 183. https://doi.org/10.1007/s42452-021-04209-Z

[3] Rezzadori, K., Benedetti, S. and Amante, E.R. (2012) Proposals for the Residues Recovery: Orange Waste as Raw Material for New Products. Food and Bioproducts Processing, 90, 606-614. https://doi.org/10.1016/j.fbp.2012.06.002

[4] Ringblom, U. (2004) The Orange Book. Tetra Pak Processing, Systems ABSE-221 86 Lund, Sweden. https://www.tetrapak.com

[5] Li, Y.O. and Komarek, A.R. (2017) Dietary Fibre Basics: Health, Nutrition, Analysis, and Applications. Food Quality and Safety, 1, 47-59.

[6] Huang, Y.L., Ma, Y.S., Tsai, Y.H. and Chang, S.K.C. (2019) In Vitro Hypoglycemic, Cholesterol-Lowering and Fermentation Capacities of Fiber-Rich Orange Pomace as Affected by Extrusion. International Journal of Biological Macromolecules, 124, 796-801. https://doi.org/10.1016/j.ijbiomac.2018.11.249

[7] Bicu, I. and Mustata, F. (2013) Optimization of Isolation of Cellulose from Orange Peel Using Sodium Hydroxide and Chelating Agents. Carbohydrate Polymers, 98, 341-348. https://doi.org/10.1016/j.carbpol.2013.06.009

[8] Lachos-Perez, D., Baseggio, A.M., Torres-Mayanga, P.C., Ávila, P.F., Tompsett, G.A., Marostica, M., et al. (2020) Sequential Subcritical Water Process Applied to Orange Peel for the Recovery Flavanones and Sugars. The Journal of Supercritical Fluids, 160, Article ID: 104789. https://doi.org/10.1016/j.supflu.2020.104789

[9] Bussolo de Souza, C., Jonathan, M., Isay Saad, S.M., Schols, H.A. and Venema, K. (2018) Characterization and In Vitro Digestibility of by-Products from Brazilian Food Industry: Cassava Bagasse, Orange Bagasse and Passion Fruit Peel. Bioactive Carbohydrates and Dietary Fibre, 16, 90-99. https://doi.org/10.1016/j.bcdf.2018.08.001

[10] Delgado-Nieblas, C., Ruiz-Beltrán, K., Sánchez-Lizárraga, J., de Jesús Zazueta-Morales, J., Aguilar-Palazuelos, E., Carrillo-López, A., et al. (2019) Effect of Extrusion on Physicochemical, Nutritional and Antioxidant Properties of Breakfast Cereals Produced from Bran and Dehydrated Naranjita Pomace. CyTA-Journal of Food, 17, 240-250. https://doi.org/10.1080/19476337.2019.1566276

[11] Bader Ul Ain, H., Saeed, F., Ahmed, A., Asif Khan, M., Niaz, B. and Tufail, T. (2019) Improving the Physicochemical Properties of Partially Enhanced Soluble Dietary Fiber through Innovative Techniques: A Coherent Review. Journal of Food Processing and Preservation, 43, Article ID: e13917.

https://doi.org/10.1111/jfpp.13917

[12] Singla, G., Krishania, M., Sandhu, P.P., Sangwan, R.S. and Panesar, P.S. (2019) Value Additon of Kinnow Industry Byproducts for the Preparation of Fiber Enriched Extruded Products. Journal of Food Science and Technology, 56, 1575-1582. 
https://doi.org/10.1007/s13197-019-03670-4

[13] Wang, S., Gu, B.J. and Ganjyal, G.M. (2019) Impacts of the Inclusion of Various Fruit Pomace Types on the Expansion of Corn Starch Extrudates. LWT, 110, 223-230. https://doi.org/10.1016/j.lwt.2019.03.094

[14] Huang, Y.L. and Ma, Y.S. (2016) The Effect of Extrusion Processing on the Physiochemical Properties of Extruded Orange Pomace. Food Chemistry, 192, 363-369. https://doi.org/10.1111/j.1365-2621.1990.tb05220.x

[15] Artz, W.E., Warren, C., and Villota, R. (1990) Twin-Screw Extrusion Modification of a Corn Fiber and Corn Starch Extruded Blend. Journal of Food Science, 55, 746-754. https://doi.org/10.1111/j.1365-2621.1990.tb05220.x

[16] Gourgue, C., Champ, M., Guillon, F. and Delort-Laval, J. (1994) Effect of Extrusion-Cooking on the Hypoglycaemic Properties of Citrus Fibre: An in-Vitro Study. Journal of the Science of Food and Agriculture, 64, 493-499. https://doi.org/10.1002/jsfa.2740640416

[17] VanSoest, P.J. and Jones, L.H.P. (1988) Analysis and Classification of Dietary Fibre. Proceedings of the 5th International Workshop, Neuherberg, April 1988, 351-370. https://doi.org/10.1515/9783112417201-038

[18] Koch, J. (1980) Formation of Monopotassium Citrate (MPC) in Frozen Concentrated Orange Juice (FCOJ) at $65{ }^{\circ}$ Brix. 31 st Annual Citrus Processors' Meeting, Lake Alfred, 10 September 1980, 245.

[19] Kimball, D.A. (1985) Crystallization of Potassium Citrate Salts in Citrus Concentrates. Food Technology, 39, 76-81.

[20] Vaidya, A.A., Gaugler, M. and Smith, D.A. (2016) Green Route to Modification of Wood Waste, Cellulose and Hemicellulose Using Reactive Extrusion. Carbohydrate Polymers, 136, 1238-1250. https://doi.org/10.1016/j.carbpol.2015.10.033

[21] Leonard, W., Zhang, P., Ying, D. and Fang, Z. (2020) Application of Extrusion Technology in Plant Food Processing Byproducts: An Overview. Comprehensive Reviews in Food Science and Food Safety, 19, 218-246. https://doi.org/10.1111/1541-4337.12514

[22] Chang, M.M., Chou, T.Y.C. and Tsao, G.T. (1981) Structure, Pretreatment and Hydrolysis of Cellulose. In: Bioenergy, Vol. 20, Springer, Berlin, Heidelberg, 15-42. https://doi.org/10.1007/3-540-11018-6 2

[23] Gilbert, I. and Tsao, G. (1983) Interaction between Solid Substrate and Cellulase Enzymes in Cellulose Hydrolysis. Annual Reports on Fermentation Processes, 6, 323-358. https://doi.org/10.1016/B978-0-12-040306-6.50017-1

[24] Wisker, E. and Feldheim, W. (1985) Dietary Fiber in Cereals. Advances in Cereal Science and Technology, 7, 169-238.

[25] Robin, F., Schuchmann, H.P. and Palzer, S. (2012) Dietary Fiber in Extruded Cereals: Limitations and Opportunities. Trends in Food Science \& Technology, 28, 23-32. https://doi.org/10.1016/j.tifs.2012.06.008

[26] Wang, J., Suo, G., De Wit, M., Boom, R.M. and Schutyser, M.A.I. (2016) Dietary Fibre Enrichment from Defatted Rice Bran by Dry Fractionation. Journal of Food Engineering, 186, 50-57. https://doi.org/10.1016/j.jfoodeng.2016.04.012

[27] Sheltami, R.M., Abdullah, I., Ahmad, I., Dufresne, A. and Kargarzadeh, H. (2012) Extraction of Cellulose Nanocrystals from Mengkuang Leaves (Pandanus tectorius). Carbohydrate Polymers, 88, 772-779. https://doi.org/10.1016/j.carbpol.2012.01.062

[28] Wang, L., Xu, H., Yuan, F., Fan, R. and Gao, Y. (2015) Preparation and Physicochemical Properties of Soluble Dietary Fiber from Orange Peel Assisted by Steam 
Explosion and Dilute Acid Soaking. Food Chemistry, 185, 90-98.

https://doi.org/10.1016/j.foodchem.2015.03.112

[29] Ozyurt, V.H. and Ötles, S. (2016) Effect of Food Processing on the Physicochemical Properties of Dietary Fibre. Acta Scientiarum Polonorum Technologia Alimentaria, 15, 233-245. https://doi.org/10.17306/J.AFS.2016.3.23

[30] Pereira, R., López, B., Diniz, S., Antunes, A., Moreno Garcia, D., Rocha Oliveira, C. and Marcucci, M. (2017) Quantification of Flavonoids in Brazilian Orange Peels and Industrial Orange Juice Processing Wastes. Agricultural Sciences, 8, 631-644. https://doi.org/10.4236/as.2017.87048 